\title{
Carbon Neutrality Ambitions and Reinforcing Energy Efficiency Through OFDI Reverse Technology Spillover: Evidence from China
}

\author{
Qizhen Wang, Tong Zhao, Rong Wang* \\ Business School, Nanjing Xiaozhuang University, No.3601 Hongjing Avenue, Jiangning District, Nanjing, China
}

Received: 1 May 2021

Accepted: 2 July 2021

\begin{abstract}
Carbon neutrality is the only way for green low-carbon development. Technological progress is an important starting point for improving energy efficiency. Through scientific and technological innovation, improving energy efficiency is a practical way to achieve the goal of carbon neutralization. Due to the limitation of data and index selection, there is no qualitative analysis of carbon neutrality in this paper. Compared with previous studies, the paper has the following contributions: Firstly, the energy efficiency score of China's provincial level is measured with the DEA method and it is found that the average energy efficiency score of the eastern region is the highest, followed by the western region, and finally the central region. The results also show that the energy efficiency is not in accordance with the economic growth. The regions with higher energy efficiency scores are not always economically developed because of huge energy consumption supporting the economic development. Secondly, the Tobit method is used to study the impact of the reverse technology spillover effect of OFDI on China's energy efficiency. The results show that the spillover effect has a significant positive effect on the improvement of China's energy efficiency, and has a positive impact on the eastern and western regions, but has no significant impact on the western region. Finally, we put forward some policy recommendations to increase energy efficiency to approach carbon neutrality and thus promote green economic development. This paper enriches the content of energy economy, the research method is innovative, and the conclusion is more scientific.
\end{abstract}

Keywords: energy efficiency, carbon neutrality, super-efficiency DEA, OFDI

\section{Introduction}

The economic development of emerging economies has the characteristics of energy-intensive, that is, the rapid economic growth has been accompanied

*e-mail:wxr920@163.com by huge energy consumption. The energy systems in most of these countries are based on fossil fuels and the consumption of fossil fuels is the main source of increasing carbon dioxide emissions, which has a negative impact on the ecological environment, atmospheric temperature and sustainable economic development. To solve this problem, many emerging economies take carbon neutralization as an important 
measure to protect the ecological environment. Through carbon neutralization, they can accelerate the green low-carbon transformation of energy system, protect the ecosystem and environment, and bring new economic growth points to the world. According to the Intergovernmental Panel on Climate Change (IPCC), carbon neutrality refers to that an organization achieves the balance of carbon dioxide emissions and absorption through carbon dioxide elimination technology, or net zero $\mathrm{CO} 2$ emissions. For emerging economies, economic development is the fundamental way to solve national problems. How to reduce carbon dioxide emissions or even achieve zero emissions in the process of economic development is a problem that countries have to think about.

To achieve carbon neutrality, we should radically reduce fossil energy consumption. It is conducive to improving environmental quality, protecting the ecological environment, promoting the development of green economy, and strongly supporting the medium and high-speed growth of China's economy. To achieve carbon neutrality, we should develop high value-added and low energy consumption industries to replace those traditional industries with low added value and high energy consumption, establish an industrial system with green and low-carbon circular development, and realize the transformation and upgrading of the industrial structure. To achieve carbon neutrality, we should abandon the development path that the growth rate of energy consumption is higher than that of economic development in the process of industrialization and urbanization in developed countries, and seek a new development path of industrialization and urbanization characterized by high economic growth and low energy consumption.

As one of the important emerging economies in the world, China's economic aggregate and energy consumption has been growing rapidly. China ranked the world's top energy-related $\mathrm{CO}_{2}$ emissions in 2019 according to the International Energy Agency (IEA). Therefore, the development of China's economy is accompanied by the increase of carbon dioxide emissions, climate warming, air pollution and other enviromental issues. In 2020, China has clearly put forward a long-term climate goal at the UN General Assembly, that is, carbon dioxide emissions should reach the peak by 2030, and strive to achieve carbon neutrality by 2060 . This goal means that the new growth of energy demand is mainly met by the new non-fossil energy supply, ensuring that coal, oil, natural gas and other fossil energy almost no longer increase. At the same time, we should build a near zero emission energy system with new energy and renewable energy as the main body, and ultimately reduce the emissions of conventional pollutants in fossil energy consumption. In order to achieve this goal, it is necessary to improve the energy structure and energy efficiency. The development of China's energy structure has gone through three stages. The first stage is dominated by coal. The second stage is the diversified development of fossil energy and non-fossil energy. The current stage is dominated by non-fossil energy. On the basis of optimizing the existing energy structure, improving energy efficiency is an important measure to achieve the goal of carbon neutrality. At the micro level, improving energy efficiency can provide more opportunities for individuals [1], reduce enterprise operating costs, expand technology investment, and improve product quality and productivity [2]. At the macro level, improving energy efficiency can reduce air pollution; improve environment, carbon neutrality and sustainable economic development [3-5].

The main driver for improving energy efficiency is the technological progress. For the emerging economies, outward foreign direct investment (OFDI) is an important form to undertake international technology transfer and technology diffusion. Due to the inextricable connection between OFDI companies and the home country, it will transfer technology to the home country through reverse technology spillovers, drive domestic companies to invest in $\mathrm{R} \& \mathrm{D}$ and improve technological innovation. The mechanism of the impact of OFDI on energy efficiency is that OFDI companies may improve energy efficiency through increasing energy-saving R\&D investment and reducing production costs to move toward the international market. On the other hand, the incumbent OFDI companies will adopt international advanced equipment, introduce energy-saving technologies, and then improve energy efficiency in order to maintain their position in the international market. Due to the rebound effect [6], the technological progress may increase energy efficiency while stimulating consumers and producers to generate more energy demand. As a result, the energy consumption may not be reduced as expected or even increased, which is negatively related to the improvement of energy efficiency. Therefore, it is of great practical significance to study the impact of reverse technology spillover effects of OFDI on energy efficiency in the context of carbon neutral. Scholars at home and abroad have carried out a lot of research in the following aspects.

\section{Measurement of Energy Efficiency}

The earliest measurement was based on the theory of physics, using unit energy consumption to measure energy efficiency [7]. Later, a large number of scholars used energy intensity to measure energy efficiency. Energy intensity is the energy consumption per unit of effective output. Energy intensity is negative related to energy efficiency [8]. Some scholars also used the reciprocal of energy intensity, energy productivity, to measure energy efficiency. Energy efficiency was directly proportional to energy productivity, but inversely proportional to energy intensity. The purpose of improving energy efficiency is to save energy. Energy intensity indicators reflect not only energy saving, but 
also the transformation of economic structure. Based on energy intensity indicators, some scholars further used indicator decomposition methods to decompose energy efficiency and put forward specific energy policy suggestions [9]. Only when the change of energy-output ratio is caused by the increase in energy productivity, energy intensity may measure energy efficiency. In fact, changes of energy-output ratio were usually attributed to many other different factors [10]. Therefore, scholars will use another method, model estimation, to measure energy efficiency.

Based on economic theory, the model estimation method establishes a model to describe the relationship between energy input and related indicators, which also includes the joint effect of energy consumption and other production factors such as labor and capital. There are two methods of model estimation, one is a parametric method and the other is a non-parametric method. Common parameter models usually adopt the Cobb-Douglas production function incorporating stochastic frontier technology (SFA) to calculate energy efficiency. $\mathrm{Hu}$ and Honma [11] used the SFA method to estimate the energy efficiency of OECD countries. The results showed that most industries had little change in the low efficiency trend. However, inefficiencies in the construction industry, paper industry and textile industry had increased significantly. The metal industry was the only industry where inefficiency has declined. When using the SFA method to investigate the Indian paper industry, Haider and Bhat [12] found that there would be huge potential for improving energy efficiency. The inefficiency effect model showed that the industrial structure and the capital intensity were positive related to energy efficiency, while labor productivity was not related to energy efficiency.

The DEA method proposed by Charnes et al. [13] is a non-parametric method, which has been widely used to evaluate the efficiency value. The measures of efficiency in DEA are radial or non-radial. The radial measures have classical Charnes-Cooper-rodes model and Banker-Charnes-Cooper (BCC) model [14]. The non-radial measures have slack-based measurement (SBM) [15]. Nowadays, the DEA method has been adopted in different fields such as mathematics, management science, operations research, and energy. Xiao and Mei [16] conducted the research on the energy efficiency at the country level. At the industry level, Tang et al. [17] on tourism, Abbas et al. [18] on Pakistan agriculture both involved energy efficiency. The DEA method can only analyze efficient DMUs (efficiency score $=1$ ), but cannot analyze inefficient DMUs (efficiency score $>1$ ). Andesen and Petersen [19] proposed a super-efficient DEA (SE-DEA) method which did not include the decision-making unit itself in the set of decision-making units, that is, using linear combination of input and output indicators of other decision-making units to replace that of this decision-making unit. It overcame shortcomings that traditional DEA model could only distinguish between efficient and inefficient DMUs and could not compare and sort efficient DMUs. When analyzing energy efficiency in Turkey, Ervural et al. [20] tried to use OLS regression and super-efficiency DEA model to reveal environmental variables that affected energy efficiency. The results showed that Yalova, Kilis, and other regions had the highest energy efficiency, followed by the Aegean Region and The South Eastern Anatolia Region. The plausible explanation was that these areas had high technological level and great potential for renewable resource utilization. Gökgöz and Erkul [21] analyzed the energy efficiency of European countries with SEDEA model. They found that regions such as Eastern Europe, the Baltic countries had lower energy efficiency scores, while regions such as Northern Europe, Western Europe and Scandinavia had higher energy efficiency scores. The possible reason was that the former could not adjust polices with the EU's energy policy due to their low technical level, while the latter could well adapt to the changes in the EU's energy policy. They suggested that European countries should reduce their dependence on fossil energy, accelerate energy legislation, and achieve clean energy goals of Eastern Europe and the Baltic countries should also actively improve their technological level.

\section{Technological Progress, Energy Efficiency and Carbon Neutrality}

For emerging economies, energy and environmental problems are costs of extensive economic development in the early stages of industrialization, which have become prominent with the economic development. An important way to solve the contradiction between economy and energy is to optimize the energy structure, improve energy efficiency, and ultimately achieve carbon neutrality. In terms of energy efficiency, technological progress is the main driving force to improve it, while technological backwardness hinders the improvement of energy efficiency [22]. FisherVanden et al. [23] found that technological progress was conducive to the improvement of enterprises' absorptive capacity, prompting enterprises to better absorb FDI technology spillovers, thereby promoting the improvement of energy efficiency. Zhao et al. [24] found that foreign direct investment was important to reduce China's energy consumption. The advanced technology and management expertise introduced by multinational companies and their demonstration effects on local enterprises had led to a decrease in energy intensity.

To achieve carbon neutrality means the improvement of technology and energy efficiency. Guptaa and Garg [25] set four scenarios based on different development and deep decarbonization conditions, business-as-usual (BAU), development first (DEVF), carbon neutrality (CNT) and synchronous (SYNCH). The results showed that BAU had the lowest energy efficiency, followed by DEVF, followed by SYNCH, while CNT had the highest energy efficiency. In the carbon 
neutral transformation of residential buildings, more attention is paid to technical improvement and various strategic arrangements. Garriga et al. [26] attempted to use various technologies to carry out carbon neutral transformation of residential communities. Firstly, the best cost-effective energy efficiency measures were determined, which achieved energy saving of $57 \%$ and peak power demand saving of $29 \%$ respectively, and ultimately reduced the overall energy demand of community buildings.

In the research of technological innovation and production process, carbon neutralization is more closely related to technological progress. As bioelectrochemical hydrogen production technology, microbial electrolysis cell (MEC) technology also needs the external power supply, which leads to that the whole MEC system is not sustainable. This has been the main obstacle to the practical application of MECs. In order to overcome the obstacle, Yang et al. [27] introduced a self-sustainable MEC technology by combining traditional MECs with advanced carbon neutral technologies, such as solar, microbial, osmotic and thermoelectric energy (and their combinations). Mandova et al. [28] used carbon capture and storage technology to transform steel plants, and found that it could significantly reduce the emission intensity of steel plants. Specifically, biomass utilization can achieve up to $20 \%$ carbon dioxide emission reduction target. It is worth noting that the future application of carbon capture and storage technology in steel-making industry will be affected by non-economic conditions such as regulations, public acceptance, actual carbon dioxide storage capacity and the progress of other mitigation technologies.

\section{OFDI and the Technological Progress of the Home Country}

There existed transnational technology spillovers in international trade in the early studies. Potterie and Lichtenberg [29] further found that foreign direct investment had reverse technology spillover effects based on Coe and Helpman [30] when using the selected OFDI data from developed countries. The reverse technology spillover effects were beneficial to the improvement of technology level in the home country, especially when host country was R\&Dintensive. Driffield and Love [31] found that technology in the domestic sector may spill to foreign multinational companies, but these spillover effects were influenced by the industry spatial concentration and were restricted to relatively $\mathrm{R} \& \mathrm{D}$-intensive sectors. This confirms the existence of OFDI reverse technology spillover effects. Chen and $\mathrm{Li}$ [32] conducted an empirical study using data from developing countries, and found that developing country companies had knowledge-seeking motivations when investing abroad. The investment of these multinational enterprises in the host country market with rich technological resources would help improve the technology of their home country because the subsidiary would affect the parent company through reverse technology spillover effects and increased the parent company's domestic R\&D expenditure.

Few studies on reverse technology spillover effects of OFDI have been made and most of these studies are the impact of OFDI which is flowed from emerging countries to developed countries on the technological progress of emerging countries. Some scholars have studied the influencing direction of reverse technology spillover effects of OFDI on the home country after confirming the existence of OFDI reverse technology spillover effects. Most scholars found that OFDI was negative related to technological progress of the home country. Multinationals conduct the technological imitation and technological improvement through demonstration effects, link effects, competition effects, and personnel flow effects to improve the level of R\&D and increase the productivity of society when they invest in developed countries [33]. The acquisition is one of the ways for companies to expand their foreign investment. Emerging economies can get new core technologies to make up the shortage in technology, improve competitiveness and change the technology portfolio [34]. Multinational companies have become the source and recipient of cross-border knowledge flow when they make foreign direct investment. While obtaining foreign technology and market information, they also carry out more research and development activities. In addition, foreign direct investment in the form of joint ventures is often more beneficial to domestic R\&D because it provides an important way for companies to obtain more extensive knowledge [35].

Some scholars also found that it is not uncertain for the relationship between OFDI and technological progress of home country, the relationship between OFDI and the technological progress of the home country was uncertain, because OFDI and home country R\&D have complementary effects and substitution effects [36]. Zhou et al. [37] found that there were three channels for OFDI in emerging economies to spillover to the home country: home country, supplier and customer. The OFDI positively affected the domestic green TFP, but the influencing coefficient was relatively small. The plausible explanation was the lack of absorption capacity of provinces which invested abroad. If the province maximized the use of green technologies and strengthened the construction of local environmental regulations, it may increase the reverse technology spillover effects of OFDI. The absorptive capacity of home country was of great importance in technology spillover effects of OFDI. Tang and Altshuler [38] found that multinational corporations had technology spillover effects on home countries and the absorptive capacity played a key role in technology spillovers.

To sum up, previous literature has done a lot of research on the measurement of energy efficiency, and discussed the relationship between technological progress and energy efficiency. However, there are few studies on the impact of reverse technology spillover 
of outward foreign direct investment on domestic energy efficiency, especially in the context of carbon neutrality. Most of studies are almost quantitative analysis at the industry level of quantitative analysis, and the qualitative analysis is less at the regional level. Compared with the previous literature, the contributions of this paper are as follows: (1) This paper discussed the impact of the reverse technology spillover of OFDI on energy efficiency in the home country against the background of carbon neutrality, which enriched the research on energy efficiency and energy consumption in developing countries. (2) This paper estimated China's energy efficiency at the regional level and made an empirical analysis in the eastern, central and western regions. It not only provided more freedom for statistical calculation and made research from a micro perspective, but also explored the special information in regional economic development, which made the empirical results have a broader policy application space. (3) This paper carried out the research in two steps. The first step was to estimate the energy efficiency values of 30 provinces in China with the super-efficiency DEA model. The second step was to explore the influence of reverse technology spillovers of OFDI on China's energy efficiency using the Tobit model. The measurement indicators and empirical methods were more mature, and the conclusions were more scientific and comprehensive.

\section{Material and Methods}

\section{Super Efficiency DEA Model}

Suppose that each province is a decisionmaking unit and there are $s$ decision-making units $D M U\left\{D M U_{j}: 1,2, \ldots, s\right\}$ in our study. There are $m$ input variables and $n$ output variables, where $x_{i j}(1,2$, $3, \ldots, m)$ is the ith input variable of $j$ th province and $y_{i j}(1,2,3, \ldots, n)$ is the $r t h$ output variable of $j t h$ province. The criteria for selecting input variables and output variables is that input variables should include all factors that affect output and output variables should reflect the results that can be achieved by production. When selecting input-output data, it is necessary to classify completely replaceable factors or completely complementary factors into the same category, that is, minimizing substitution or complementary between two factors [39-40]. The formula is as follows:

$\min \theta$

$$
\text { s.t. }\left\{\begin{array}{c}
\sum_{j=1}^{s} \lambda_{j} x_{i j} \leq \theta x_{i j_{0}}, i=1,2,3, \ldots, m \\
\sum_{j=1}^{s} \lambda_{j} y_{r j} \geq y r j_{0}, r=1,2,3, \ldots, n \\
\lambda_{j} \geq 0, j=1,2,3, \ldots, s
\end{array}\right.
$$

...where $\lambda_{1}, \lambda_{2}, \lambda_{s}$ are vector variables. $\theta$ is the energy efficiency. The higher the value, the higher the energy efficiency will be. The two slack variables $s_{i}^{-}$and $s_{r}^{+}$ are introduced and $\varepsilon$ is the non-Archimedes infinitesimal. For multiple effective decision-making units (efficiency score is 1), the super-efficiency DEA model does not include the decision-making unit itself in the set of decision-making units during the evaluation. The super-efficiency DEA model is

$$
\begin{array}{r}
\min \theta-\varepsilon\left(\sum_{i=1}^{m} s_{i}^{-}+\sum_{r=1}^{s} s_{r}^{+}\right) \\
\text {s.t. }\left\{\begin{array}{l}
\sum_{j=1}^{s} \lambda_{j} x_{i j}+s_{i}^{-}=\theta x_{i k_{0}}, i=1,2,3, \ldots, m \\
j \neq k \\
\sum_{j=1}^{s} \lambda_{j} y_{r j}-s_{r}^{+}=y_{r k}, r=1,2,3, \ldots, n \\
j \neq k \\
\lambda_{j}, s_{i}^{-}, s_{j}^{+} \geq 0, j=1,2,3, \ldots, s
\end{array}\right.
\end{array}
$$

\section{Data Processing and Selection}

The article uses the provincial-level data of China which are from China Statistical Yearbook, China Science and Technology Statistical Yearbook, Statistical Bulletin of China's Outward Foreign Direct Investment, China Economic Network Statistical Database, the World Bank and the United Nations Conference on Trade and Development Database (UNCTAD) during 2004-2017. Tibet, HongKong, Macau, and Taiwan are not included because of incomplete data. On the basis of the existing literature, we calculate the super efficiency DEA score for each province in consideration of the features of China's energy consumption and regional openness. The input variables include capital $\left(X_{1}\right)$, labor $\left(X_{2}\right)$ and energy $\left(X_{3}\right)$, and the output variables include GDP $\left(Y_{1}\right), \operatorname{SO} 2\left(Y_{2}\right)$ and industrial waste water $\left(Y_{3}\right)$. Both input variables and output variables are listed in Table 1. Capital is measured by the fixed capital stock, which is calculated by the fixed capital formation index based on the year 2004 with the perpetual inventory method. The formula is $K_{j t}=K_{j t-1}\left(1-\delta_{j t}\right)+I_{j t}$, where $K_{j t}$ is the fixed capital stock of the $j$ th province in the $t$ th year, $I_{j t}$ is the fixed capital formation of the $j t h$ province in the $t$ th year and $\delta_{j t}$ is the depreciation rate of fixed capital of the $j t h$ province in the $t$ th year. Labor input is the number of employees in each province. Energy input is energy consumption in each province. GDP is calculated through the GDP deflator based on the year 2004. $\mathrm{SO}_{2}$ is the sulfur dioxide emissions, and the industrial waste water is the total waste water discharge.

The reverse technology spillover effects is measured by the foreign R\&D capital stock obtained from China's OFDI. The perpetual inventory method is adopted and 
Table 1. Regional energy efficiency evaluation index system.

\begin{tabular}{|c|c|c|}
\hline & Index category & Index form \\
\hline \multirow{3}{*}{$\begin{array}{c}\text { Input } \\
\text { index }\end{array}$} & Capital $\left(\mathrm{X}_{1}\right)$ & Capital stock \\
\cline { 2 - 3 } & Labor $\left(\mathrm{X}_{2}\right)$ & Employees \\
\cline { 2 - 3 } & Energy $\left(\mathrm{X}_{3}\right)$ & Energy consumption \\
\hline \multirow{3}{*}{$\begin{array}{c}\text { Output } \\
\text { index }\end{array}$} & $\mathrm{GDP}\left(\mathrm{Y}_{1}\right)$ & Regional GDP \\
\cline { 2 - 3 } & $\mathrm{SO}_{2}\left(\mathrm{Y}_{2}\right)$ & $\mathrm{SO}_{2}$ emission \\
\cline { 2 - 3 } & $\mathrm{WD}\left(\mathrm{Y}_{3}\right)$ & Total waste water discharge \\
\hline
\end{tabular}

the formula is: $S_{f t}=\sum \frac{o f d i_{f t}}{k_{f t}} S_{f t}^{d}$, where $S_{f t}$ represents the reverse technology spillover effect in $t$ th year. ofdi $i_{f t}$ represents China's outward foreign direct investment to $f t h$ country in $t$ th year. $k_{f t}$ is the fixed capital formation of the $f t h$ country in the $t$ th year. $S_{f t}^{d}$ represents the R\&D capital stock of $f t h$ country in $t$ th year. We then calculate the reverse technology spillover effect at the provincial level and the formula is: $S_{i f t}=\rho S_{f t}$, where $S_{i f t}$ represents the reverse technology spillover effect of each province in tth year. $\rho$ is the proportion of each province's OFDI to China's OFDI.

Based on previous literature, this paper adds patents, energy structure, industrial structure, human capital, urbanization level, fiscal expenditure and openness degree to the model as control variables. Among them, patents are represented by the amount of patents granted. Energy structure is the coal consumption divided by total energy consumption. Industrial structure is the ratio of the output value in the secondary industry to the total output value. Human capital is the proportion of high school graduate numbers to the total number of people. The level of urbanization is the urban population divided by the total population. Fiscal expenditure is the proportion of provincial fiscal expenditure to GDP. The degree of openness (open) is measured by the proportion of the total imports and exports in each province to the current GDP. The Tobit regression equation is as follows:

$$
\begin{aligned}
& \text { dea }_{i t}=\alpha+\beta_{1} \text { ofdi }_{i t}+\beta_{2} \text { patent }_{i t}+\beta_{3} \text { energy }_{i t}+\beta_{4} \text { industry }_{i t} \\
& +\beta_{5} \text { human }_{i t}+\beta_{6} \text { urban }_{i t}+\beta_{7} \text { fined }_{i t}+\beta_{8} \text { open }_{i t}+\mu_{i t}
\end{aligned}
$$

...where $i$ is province and $t$ is year. $\alpha, \beta_{1}, \beta_{2}, \quad \beta_{3}, \beta_{4}, \beta_{5}$, $\beta_{6}, \beta_{7}, \beta_{8}$, are the regression coefficients, and $\mu$ is the residual.

\section{Results and Discussion}

\section{Analysis of Temporal and Spatial Differences in Regional Energy Efficiency}

Using the super-efficiency DEA model, we obtain energy efficiency scores of China and show them in
Table 2. In addition, we display energy efficiency scores for each year based on ArcGIS. In order to save space, Fig. 1 shows the energy efficiency scores for some selected years.

The national energy efficiency scores have a little fluctuation and have a downward trend in recent years. The first obvious fluctuation was during the 2008 financial crisis, which caused a great impact on national income and energy consumption. The second obvious fluctuation was the first year of China's Twelfth Five-Year Plan period (2011-2015). In this year, the government further introduced the policies of energy conservation, emission reduction and environmental protection. The energy consumption per unit GDP would drop $16 \%$, and the main pollutant discharged amount would reduce $8 \%$ in the following 5 years. For energy saving and emission reduction, each province made polices to restrict industries that were highly polluted, energy intensive or wasteful of natural resources. At the same time, these policies greatly weakened the regional economic development, which had a negative effect on the energy efficiency improvement.

The lowest energy efficiency was in the central region. The energy efficiency score of western region was greater than that of eastern region before 2011, and the western region lagged far behind the eastern region after 2011. The plausible explanation was that the eastern region had a vital role in China's economic growth. In order to achieve the goal of the economic development, it consumed a lot of energy but ignored the improvement of energy efficiency. The eastern region has begun to realize the seriousness of energy problems during the Twelfth Five-Year Plan period. It took measures to change economic growth patterns, from extensive growth to intensive growth, to the improve energy efficiency.

There were also obvious differences in energy efficiency scores inside the eastern region. Guangdong Province had the highest average energy efficiency score among the eastern provinces, and the efficiency score exceeded 1 in all years. Tianjin and Beijing had the second highest average energy efficiency scores, 1.027 and 1.023 respectively. The average scores of the energy efficiency in Hainan and Shandong were greater than 1 , while the energy efficiency scores were less than 1 in some years. The energy efficiency score of Hebei province, 0.978, was the lowest in the eastern region, which was also lower than the national level. Many cities in Hebei border on Beijing. In order to prevent the industrial pollution, many industries in Beijing are located in the neighboring cities of Hebei. This increases Hebei's resource consumption and decreases the energy efficiency due to its low level of technology. Energy efficiency scores in the central region had little fluctuation. The average energy efficiency scores of Jiangxi and Hunan were larger, exceeding 1. The energy efficiency scores of other provinces were lower than 1. The average energy efficiency scores of Guangxi, Guizhou, Qinghai and Ningxia were greater than 1 
in the western region, where Guangxi and Ningxia had experienced significant declines. The average energy efficiency scores of Shaanxi, Gansu and Xinjiang were less than 1, which have also declined significantly in recent years. With the migration of heavy industries and high-energy-consuming industries to the interior area and the introduction of more stringent energy-saving and emission-reduction policies, it will put greater pressure in raising the energy efficiency in the western region.

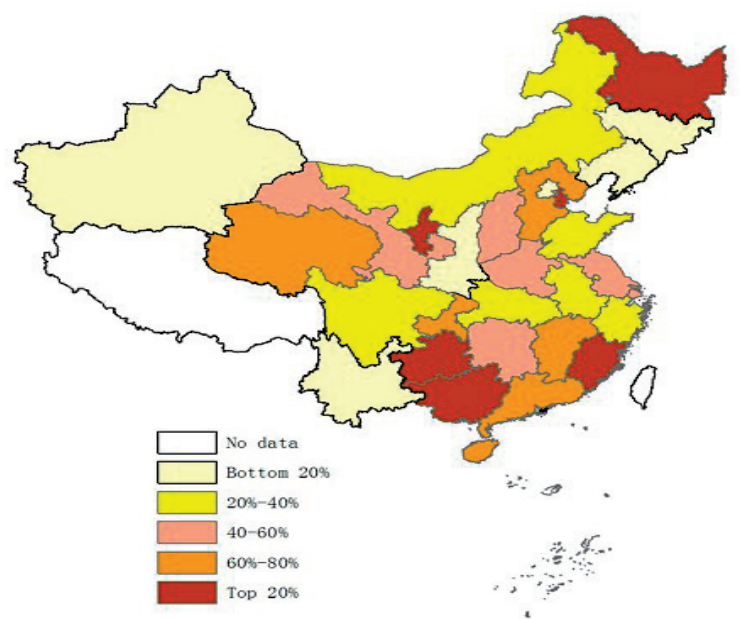

a. 2004

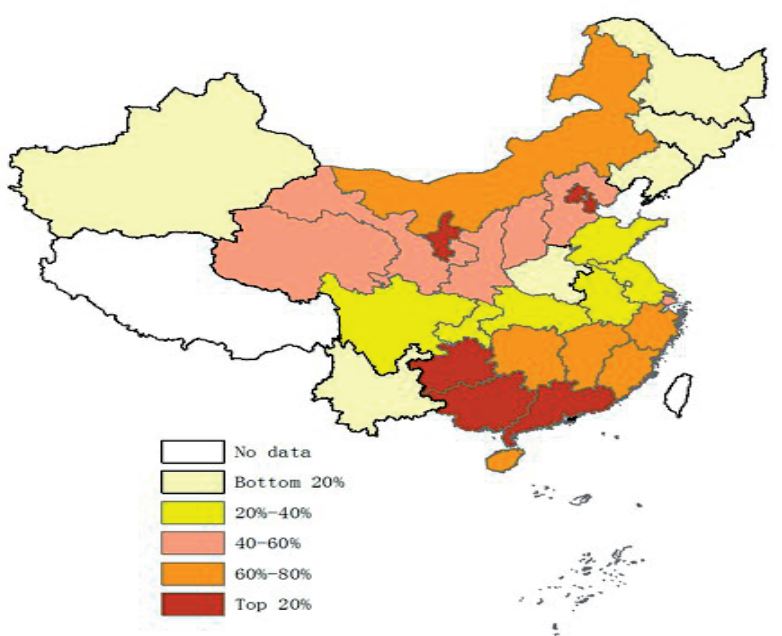

c. 2011

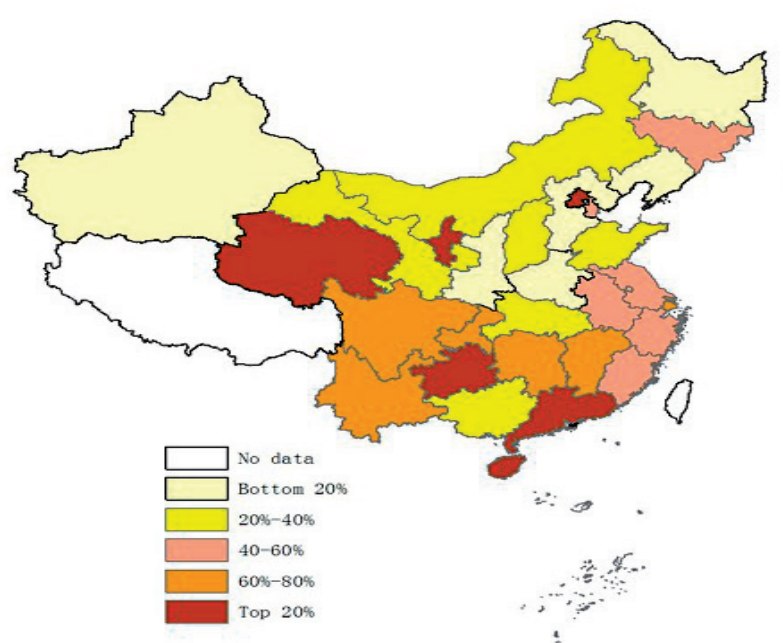

e. 2016

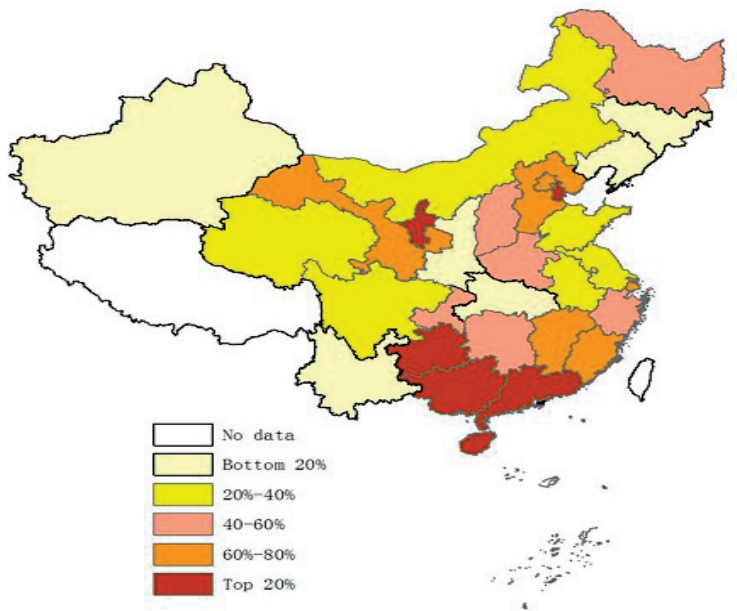

b. 2005

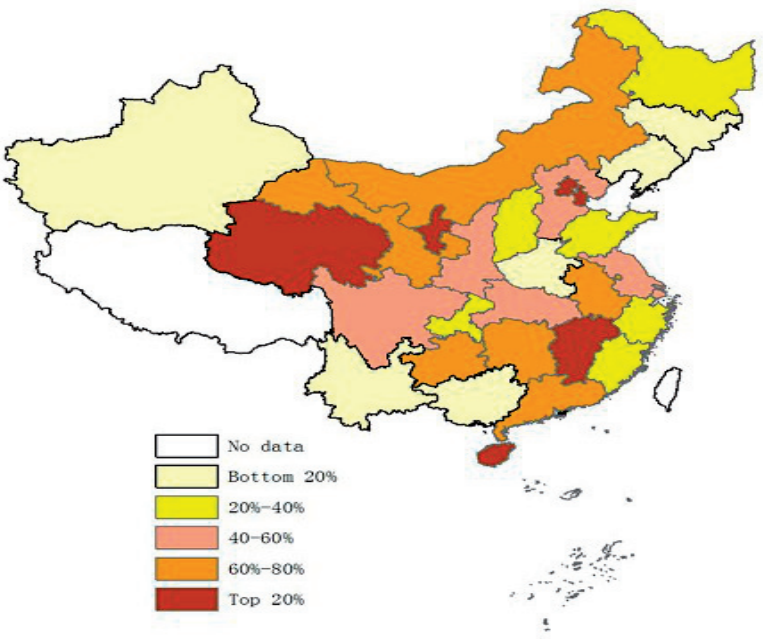

d. 2012

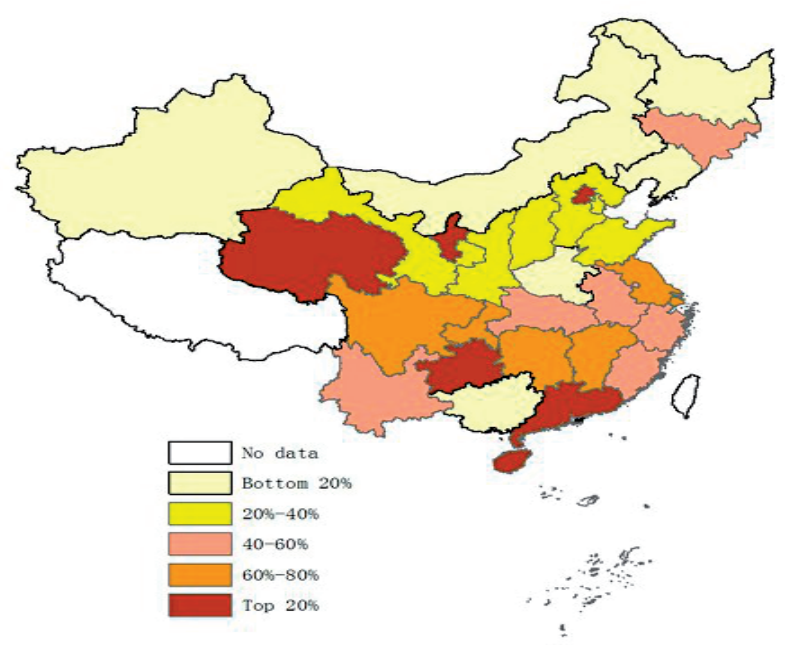

f.2017

Fig. 1. Regional energy efficiency in China. 


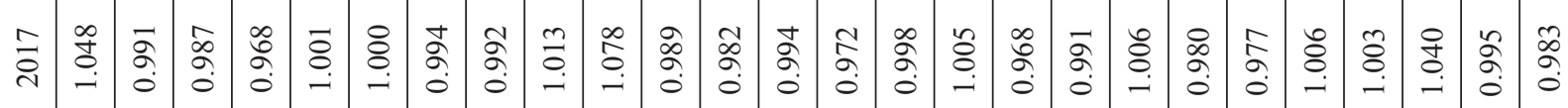

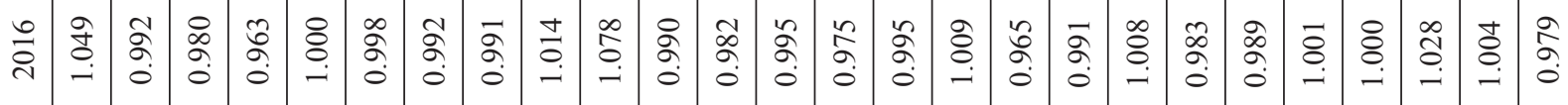

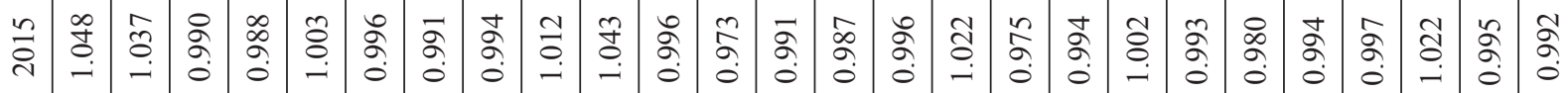

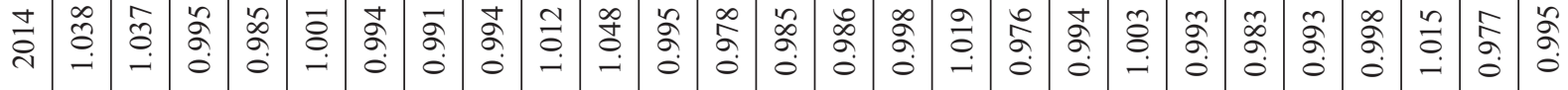

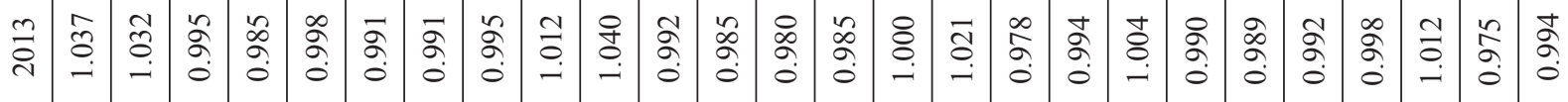

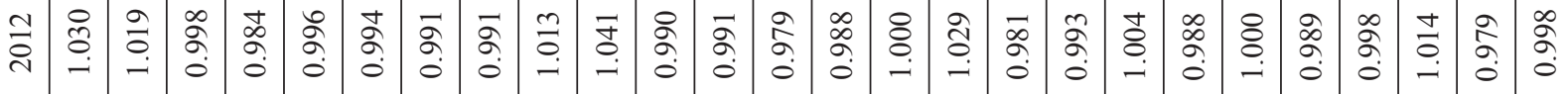

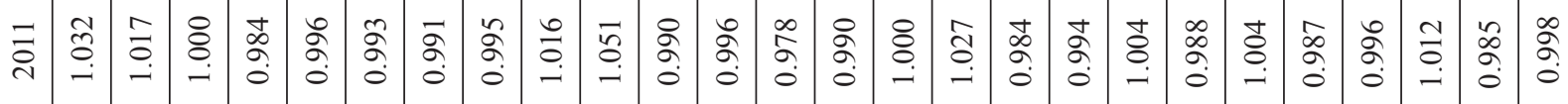

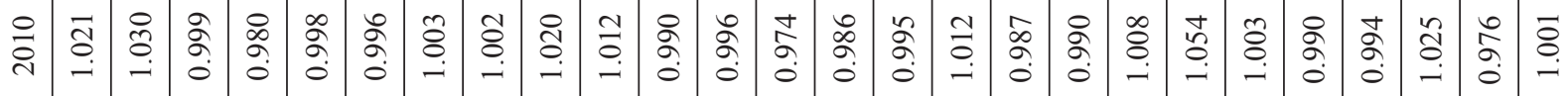

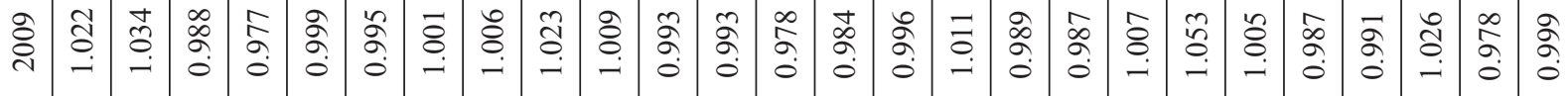

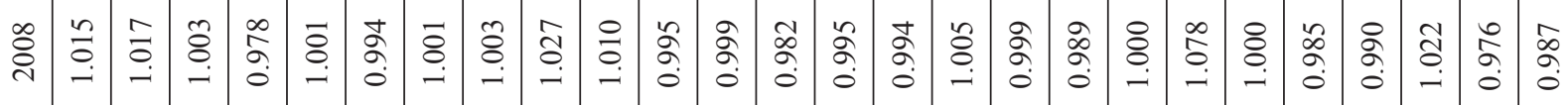

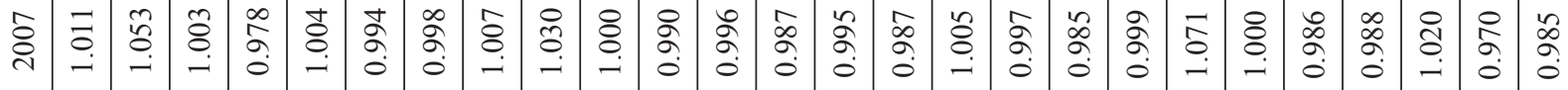
\&่̊

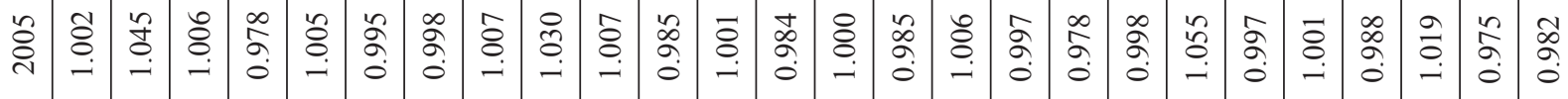
岸 


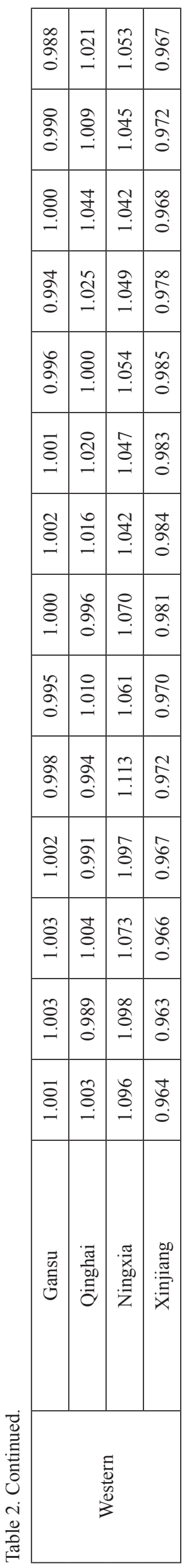

Table 3. Variables Description Statistics.

\begin{tabular}{|c|c|c|c|c|c|}
\hline Variable & Obs & Mean & Std.Dev. & Min & Max \\
\hline OFDI & 420 & 11.084 & 1.929 & 5.201 & 15.755 \\
\hline Patent & 420 & 9.081 & 1.636 & 4.248 & 12.714 \\
\hline Energy & 420 & 0.65 & 0.188 & 0.066 & 1.144 \\
\hline Industry & 420 & 0.467 & 0.081 & 0.191 & 0.614 \\
\hline Human & 420 & 0.079 & 0.046 & 0.0232 & 0.312 \\
\hline Urban & 420 & 3.924 & 0.261 & 3.249 & 4.495 \\
\hline Fined & 420 & 0.213 & 0.094 & 0.076 & 0.626 \\
\hline Open & 420 & 0.243 & 0.229 & 0.011 & 1.056 \\
\hline
\end{tabular}

\section{Analysis of OFDI's Impact on the Energy Efficiency}

This section uses the Tobit regression method to study the impact of OFDI on the energy efficiency. Dependent variables are the energy efficiency scores of each province from 2004 to 2017. The independent variables are the reverse spillover effect of OFDI, patents, energy structure, industrial structure, human capital, urbanization level, fiscal expenditure and openness degree. The descriptive statistics are shown in Table 3.

Models (1)-(3) are results of panel Tobit regression with gradually adding variables. Most of the variables have no significant changes in the sign and size of the regression coefficients after adding other variables. Table 4 reports the results. The analysis is as follows:

The regressions of three models show that the reverse technology spillover effect of OFDI positively affects the energy efficiency. The average annual growth rate of China's non-financial outward foreign investment stock was $43.76 \%$ during 2004-2017. The prosperity of the outward foreign investment is not only conducive to obtaining advanced technology and raising productivity for the host country, but also conducive to the optimizing and transformation of industrial structure of the home country. Developed countries have taken the lead in optimizing the industrial structure, and their OFDI create favorable conditions for micro-economic agents to establish an international production system. Compared with developed countries, developing countries do not have the advantage of the advancement of industrial structure. They upgrade the industrial structure through the establishment of international production system, that is, they optimize the industrial structure through OFDI. The OFDI of emerging countries have not had the monopolistic advantage or ownership advantage and the motivation for foreign investment is strategic asset-seeking. Technology-seeking investment is one of the strategic asset-seeking investments in developing countries. Multinational companies of developing countries employ the R\&D personnel from host country, track 
cutting-edge technology information, obtain advanced knowledge, or cooperate with local $R \& D$ institutions to actively obtain reverse technology spillover effects, which can make up the shortage of technology spillover effects that weaken with increasing spatial distance [41]. Developed countries have advanced energy technology and strict energy consumption standards. Multinational enterprises of developing countries will learn energy technologies from developed countries in order to save energy and reduce emissions in the process of adapting the host country market. The increase in energy efficiency and energy saving of subsidiaries will also prompt the parent company to upgrade the energy technology and improve the energy efficiency, because the improvement of energy efficiency will bring considerable economic and social benefits to multinational companies.

Patents negatively affect the energy efficiency. Most studies think that the technological progress brought about by both technology innovation and technology introduction will improve energy efficiency through

Table 4. Panel Tobit model regression results.

\begin{tabular}{|c|c|c|c|}
\hline \multirow[t]{2}{*}{ Variable } & \multicolumn{3}{|c|}{ Model } \\
\hline & (1) & (2) & (3) \\
\hline \multirow{2}{*}{ OFDI } & $0.014^{* * * *}$ & $0.014^{* * *}$ & $0.015^{* * *}$ \\
\hline & $(0.01)$ & $(0.01)$ & $(0.01)$ \\
\hline \multirow{2}{*}{ Patent } & $-0.025^{* * *}$ & $-0.026^{* * *}$ & $-0.017^{* *}$ \\
\hline & $(0.01)$ & $(0.01)$ & $(0.01)$ \\
\hline \multirow{2}{*}{ Energy } & $-0.014^{* * * *}$ & $-0.015^{* * *}$ & $-0.017^{* * *}$ \\
\hline & $(0.00)$ & $(0.01)$ & $(0.01)$ \\
\hline \multirow{2}{*}{ Industry } & & $0.014^{* *}$ & $0.016^{* * *}$ \\
\hline & & $(0.01)$ & $(0.01)$ \\
\hline \multirow{2}{*}{ Human } & & 0.019 & 0.028 \\
\hline & & $(0.02)$ & $(0.03)$ \\
\hline \multirow{2}{*}{ Urban } & & & $-0.014^{* *}$ \\
\hline & & & $(0.01)$ \\
\hline \multirow{2}{*}{ Fined } & & & $0.017^{*}$ \\
\hline & & & $(0.01)$ \\
\hline \multirow{2}{*}{ Open } & & & 0.005 \\
\hline & & & $(0.01)$ \\
\hline \multirow{2}{*}{ _cons } & $0.709^{* * * *}$ & $0.703^{* * *}$ & $0.745^{* * *}$ \\
\hline & $(0.01)$ & $(0.01)$ & $(0.02)$ \\
\hline rho & 0.711 & 0.675 & 0.682 \\
\hline Wald & $30.08^{* * *}$ & $19.42^{* * *}$ & $22.99^{* * *}$ \\
\hline
\end{tabular}

Note: ***,**, and * indicate significant levels at 1,5 , and $10 \%$, respectively; the data in parenthesis are standard errors. increased productivity. A large number of researches also regard patents as an important indicator to measure technology innovation [42-43]. In fact, there is a big gap between patents and the productivity, and patents do not necessarily promote productivity improvement [44]. During the transition period from a planned economy to a market economy in China, the market has become the main body of resource allocation. Marketization has given enterprises more operational autonomy, and the reform has stimulated enterprise managers to adopt new technologies to reduce costs and promote technology innovation. Since 2005, the number of patent applications and authorizations in China has increased significantly. But at the same time, there are also the problems of low proportion of invention patents and low conversion rate of patent outcomes. Therefore, the impact of patents on the productivity may remain uncertain. On the other hand, the existence of the rebound effect may cause negative effects of expanding energy consumption and reducing energy efficiency to exceed positive effects of reducing energy consumption and improving energy efficiency. The improvement of the energy efficiency may achieve the goal of energy saving in the short term, but may lead to higher energy consumption in the long term. Broberg et al. [45] explored the energy rebound effect in Sweden using a computable general equilibrium model and found that it was between $40 \%$ and $70 \%$. Jin [46] used Korean data and found that the rebound effect were $38 \%$ in the short term and $30 \%$ in the long term. The rebound effect of air conditioners was $57-70 \%$, and refrigerators had the combined effect including rebound and income effects. Lin and Liu [47] found that the energy rebound effect of urban residential buildings in China was between $66.5 \%$ and $88.5 \%$, while the energy rebound effect of rural residential buildings was between $127.0 \%$ and $236.3 \%$. The former had an upward trend, while the latter had a downward trend. The existence of the energy rebound effect makes the technological progress have the possibility to increase energy consumption, which does not support energy saving and has an adverse effect on energy efficiency.

The industrial structure has a positive impact on the energy efficiency. Since the reform and opening up, China's industrial structure has been important changes. The proportion of the second industrial increment in value decreased from $45.9 \%$ in 2004 to $39.9 \%$ in 2017 , and the proportion of the tertiary industrial increment in value increased from $41.2 \%$ in 2004 to $52.7 \%$ in 2017. In the secondary industry, light industry has developed rapidly, and many provinces and regions have changed the situation dominated by heavy industry. High energy consumption industries decreased from $41.67 \%$ in 2004 to $36.23 \%$ in 2017. Meanwhile, rapid economic growth has also promoted the development of the tertiary industry, which does good to reduce energy consumption and improve energy efficiency. Fiscal expenditure positively affects the energy efficiency. The expansion of local fiscal expenditures has allowed 
Table 5. Sub-sample regression results of panel Tobit model.

\begin{tabular}{|c|c|c|c|}
\hline Variable & Eastern & Central & Western \\
\hline \multirow{2}{*}{ OFDI } & $0.023^{* *}$ & $0.011^{* *}$ & -0.002 \\
\hline & $(0.009)$ & $(0.005)$ & $(0.011)$ \\
\hline \multirow{2}{*}{ Patent } & -0.021 & -0.001 & -0.026 \\
\hline & $(0.013)$ & $(0.011)$ & $(0.021)$ \\
\hline \multirow{2}{*}{ Energy } & -0.006 & -0.001 & $-0.018^{*}$ \\
\hline & $(0.011)$ & $(0.008)$ & (0.009) \\
\hline \multirow{2}{*}{ Human } & 0.052 & 0.055 & -0.014 \\
\hline & $(0.039)$ & $(0.036)$ & $(0.054)$ \\
\hline \multirow{2}{*}{ Industry } & -0.002 & $0.051^{* * *}$ & -0.009 \\
\hline & $(0.016)$ & $(0.007)$ & $(0.017)$ \\
\hline \multirow{2}{*}{ Urban } & $-0.021^{* *}$ & $-0.017^{* *}$ & 0.006 \\
\hline & $(0.011)$ & $(0.007)$ & $(0.014)$ \\
\hline \multirow{2}{*}{ Fined } & $0.049^{*}$ & -0.007 & 0.017 \\
\hline & $(0.025)$ & $(0.023)$ & $(0.015)$ \\
\hline \multirow{2}{*}{ Open } & $0.018^{* * *}$ & -0.017 & -0.015 \\
\hline & $(0.006)$ & $(0.012)$ & $(0.021)$ \\
\hline \multirow{2}{*}{ _cons } & $0.759^{* * *}$ & $0.721^{* * *}$ & $0.711^{* * *}$ \\
\hline & $(0.035)$ & $(0.023)$ & $(0.041)$ \\
\hline rho & 0.521 & 0.775 & 0.729 \\
\hline Wald & $30.00^{* * *}$ & $95.18^{* * *}$ & $12.26^{* * *}$ \\
\hline
\end{tabular}

Note: ***,**, and * indicate significant levels at 1,5 , and $10 \%$, respectively; the data in parenthesis are standard errors.

governments to have sufficient funds to preferential financial support, which will provide R\&D funds for enterprises to carry out the technological innovation and introduce the technology. Enterprises may upgrade the industrial structure and increase the productivity and market competitiveness when improving the technology, leading to the reduction of energy consumption. Energy structure negatively affects the energy efficiency. It is obvious that the larger the energy structure index, the more coal consumption will be. The excessive proportion of coal and the backward coal-fired technology result in low energy efficiency in China. The energy endowment pattern of China's rich coal and less oil determines that China's coal consumption and its proportion will increase in the future. Therefore, adopting energy-saving technologies to increase coal efficiency is of great significance for improving energy efficiency.

Furthermore, we divide the provinces in China into eastern, central and western regions to perform the subsample regression. The results of sub-sample regression are listed in Table 5. The reverse technology spillover effect of OFDI positively affects the energy efficiency of the eastern and central regions, and the influencing degree in the eastern region is greater than that in the central region. The impact on the energy efficiency of the western region is not significant. The plausible explanation is that the eastern and central regions have a relatively high degree of economic development and market openness, and the reverse spillover effects of their multinational companies are relatively large. On the other hand, the eastern and central regions have higher energy technology, energy consumption standards and environmental protection awareness, which make them have stronger absorption capacity for the OFDI's reverse technology spillover. Therefore, the reverse technology spillover effect of OFDI on energy efficiency in the eastern and central regions exceeds that in the western region. Most provinces in the western region are relatively backward in energy technology and relatively weak in human capital and infrastructure construction. Therefore, it is not easy to use advanced foreign energy technologies from the spillovers of OFDI to improve energy efficiency.

The ratio of urban population to the total population is used as a proxy indicator of the level of urbanization, which can reflect the speed of urbanization, but cannot reflect the quality of urbanization. The level of urbanization negatively affects the energy efficiency, indicating that when the population agglomeration reaches a certain level, environmental pollution, traffic congestion and resource allocation mismatch will become prominent, which will result in ineffective use of energy and thus reduce the energy efficiency [48]. Human capital has opposite impacts for eastern and central regions and western regions, although both significance tests are not passed. The plausible explanation is that the increase in the total amount of human capital in the eastern and central regions will bring about an increase in energy-saving technology talents, therefore promoting the improvement of the energy efficiency. The western region has serious brain drain and poor innovation, which is not beneficial to the improvement of energy efficiency. The increase (decrease) of total human capital will inevitably lead to an increase (decrease) in total energy consumption, thereby offsetting (increasing) the promotion of energy efficiency by energy-saving innovative technical talents.

\section{Conclusions}

We calculate the energy efficiency scores at the provincial level of China. The results show that average energy efficiency scores greater than 1 have 11 provinces and cities. The national energy efficiency score fluctuates insignificantly, and there has been a downward trend in recent years. The energy efficiency of the eastern region is higher than that of the central and western regions, and only the eastern region has significantly improved in the sample period. The energy efficiency ranking of the eastern region provinces gradually rises to the top in the sample period, while 
the central and western provinces continue to lag behind. The reverse technology spillover effect of OFDI positively affects China's energy efficiency. The results of sub sample regression show that the reverse technology spillover effect of OFDI positively affects the energy efficiency of the eastern and central regions, and the impact on the eastern region is larger than the impact on the central region. The reverse technology spillover effect of OFDI affects insignificantly the energy efficiency. Based on the above conclusions, it can be developed that the reverse technology spillover effect of OFDI has a positive impact on China's energy efficiency, and there are large regional differences in impact. This article combines the goals of carbon neutrality and proposes the following recommendations:

China should take measures to promote goingout enterprises to invest in technology-intensive industries while keeping the stable growth of OFDI in labor-intensive industries. The host subsidies should learn pollution control techniques and environmental monitoring means from local enterprises and extend them to home country. They should attempt to develop or co-develop carbon capture and storage technology in host countries, and then pass advanced technologies back to the home country to promote the technological progress and the improvement of energy efficiency.

China's energy policy should also optimize energy consumption structure, make the new energy demand mainly meet the new non-fossil energy supply, and ensure that the fossil energy such as coal and oil will not increase. A near zero emission energy system with new energy and renewable energy should be built. The consumption of fossil energy such as coal, oil and natural gas shall be controlled at very low level, which will fundamentally reduce the emission of conventional pollutants generated in fossil energy consumption and achieve the goal of carbon neutralization.

The region should speed up the research and development of detailed carbon neutralization implementation roadmap and formulate implementation plan according to the industry, strengthening the progress supervision of carbon neutralization target through the leading group of national response to climate change and energy conservation and emission reduction. The region should rationally develop heavy industry, decrease the proportion of heavy industry, reduce energy consumption, and vigorously develop high-tech and low-energy-consuming industries. It should eliminate backward industrial technologies and equipment as much as possible, and realize the coordination and cooperation of the industrial structure upgrading, science and technology increasing and energy efficiency improvement.

As the world largest carbon emission country, China proposed a long-term climate goal at the UN General Assembly - carbon dioxide emissions would strive to reach the peak by 2030 and strive to achieve carbon neutrality by 2060 . However, there is almost no measurement of carbon neutrality due to the limitations of methods, data and index selection at present. It is necessary to use updated data to select more scientific index and more reasonable mathematical model for more in-depth and detailed research. We hope that the carbon neutrality will be measured and the differences of carbon neutrality at the provincial level would be analyzed in the future research. Based on the measurement, we will analyze the impact of OFDI reverse technology spillover on energy efficiency and carbon neutrality, and put forward appropriate policy suggestions for green economy and high-quality development.

\section{Acknowledgments}

This article was funded by the Jiangsu Provincial Social Science Foundation Project 'Research on the Spatial Layout of OFDI of Jiangsu Private Enterprises under the Supply-Side Structural Reform' (19EYB006).

\section{Conflict of Interest}

The authors declare no conflict of interest.

\section{References}

1. GARRETT-PELTIER H. Green versus brown: Comparing the employment impacts of energy efficiency, renewable energy, and fossil fuels using an input-output model. Economic Modelling, 61, 439, 2017.

2. ARRIOLA-MEDELLIN A.M., LOPEZ-CISNEROS L.F., ARAGON-AGUILAR A., ROMOMILLARES C., FERNANDEZ-MONTIEL M. Energy efficiency to increase production and quality of products in industrial processes: case study oil and gas processing center.Energy Efficiency, 12, 1619, 2019.

3. XU Y., MA S.T. Local air pollutant emission reduction and ancillary carbon benefits of $\mathrm{SO}_{2}$ control policies: Application of AIM/CGE model to China.European Journal of Operational Research, 198, 315, 2009.

4. GOH T., ANG B.W. Tracking economy-wide energy efficiency using LMDI:approach and practices.Energy Efficiency, 12, 829, 2019.

5. WIRYADINATA S., MOREJOHN J., KORNBLUTH K. Pathways to carbon neutral energy systems at the University of California, Davis.Renewable Energy, 130, 853, 2019.

6. ALBERINI A. Household energy use, energy efficiency, emissions, and behaviors. Energy Efficiency, 11, 577, 2018.

7. FARLA J.C.M., BLOK K. The use of physical indicators for the monitoring of energy intensity developments in the Netherlands, 1980-1995. Energy, 25, 609, 2000.

8. BALOCH Z.A., TAN Q., IQBAL N., MOHSIN M., ABBAS Q., IQBAL W., CHAUDHRY I.S. Trilemma assessment of energy intensity, efficiency, and environmental index: evidence from BRICS countries. Environmental Science and Pollution Research, 27, 34337, 2020. 
9. ABEELEN C.J., HARMSEN R., WORRELL E. Disentangling industrial energy efficiency policy results in the Netherlands.Energy Efficiency, 12, 1313, 2019.

10. GAMTESSA S., CHILDS J. The potential for short-term energy efficiency improvement in Canadian industries. Energy Efficiency, 12, 1937, 2019.

11. HU J.L., HONMA S. A comparative study of energy efficiency of OECD countries: an application of the stochastic frontier analysis.Energy Procedia, 61, 2280, 2014.

12. HAIDER S., BHAT J.A. Inter-state analysis of energy efficiency-a stochastic frontier approach to the Indian paper industry. International Journal of Energy Sector Management, 12, 547, 2018.

13. CHARNES A., COOPER W.W.,RHODES E. Measuring the efficiency of decision making units.European journal of operational research, 2, 429, 1978.

14. BANKER R.D., CHARNES A., COOPER W.W. Some models for estimating technical and scale inefficiencies in data envelopment analysis.Management science, 30, 1078, 1984.

15. TONE K. A slacks-based measure of super-efficiency in data envelopment analysis. European Journal of Operational Researchl, 143, 32, 2002.

16. XIAO H., MEI L. Dynamics and Inequalities in Energy Efficiency in China.Energy and Power Engineering, 11, 132, 2019.

17. TANG C., ZHONG L., JIANG Q. Energy efficiency and carbon efficiency of tourism industry in destination. Energy Efficiency, 11, 539, 2018.

18. ABBAS A., WASEEM M., YANG M. An ensemble approach for assessment of energy efficiency of agriculture system in Pakistan. Energy Efficiency, 14, 1, 2020.

19. ANDERSEN P., PETERSEN N.C. A procedure for ranking efficient units in data envelopment analysis. Management science, 39, 1261, 1993.

20. ERVURAL B.C., ZAIM S., DELEN D. A two-stage analytical approach to assess sustainable energy efficiency. Energy, 164, 822, 2018.

21. GöKGöZ F., ERKUL E. Investigating the energy efficiencies of European countries with super efficiency model and super SBM approaches. Energy Efficiency, 12, 601, 2019.

22. HUANG J., Du D.,TAO Q. An analysis of technological factors and energy intensity in China.Energy Policy, 109, $1,2017$.

23. FISHER-VANDEN K., JEFFERSON G.H., JING, K.M., JIAN Y.X. Echnology development and energy productivity in China. Energy Economics, 28, 690, 2006.

24. ZHAO Y., SHI X.,SONG F. Has Chinese outward foreign direct investment in energy enhanced China's energy security?.Energy Policy, 146, 111803, 2020.

25. GUPTAA D., GARG A.Sustainable development and carbon neutrality: Integrated assessment of transport transitions in India.Transportation Research Part D, 85, 1, 2020.

26. GARRIGA S., DABBAGHB M., KRARTI M. Optimal carbon-neutral retrofit of residential communities in Barcelona.Spain. Energy \& Buildings, 208, 1, 2020.

27. YANG E., MOHAMED H.O., PARK S.G.A review on self-sustainable microbial electrolysis cells for electrobiohydrogen production via coupling with carbon-neutral renewable energy technologies.Bioresource Technology, 320, 1, 2021.

28. MANDOVA H., PATRIZIO P., LEDUC S. Achieving carbon-neutral iron and steelmaking in Europe through the deployment of bioenergy with carbon capture and storage. Journal of Cleaner Production, 218, 118, 2019.

29. POTTERIE B.P., LICHTENBERG F. Does foreign direct investment transfer technology across borders?.Review of Economics and statistics, 83, 490, 2001.

30. COE D.T., HHLPMAN E. International R\&D spillovers. European economic review, 39, 859, 1995.

31. DRIFFIELD N.,LOVE J.H. Foreign direct investment, technology sourcing and reverse spillovers.The Manchester School, 71, 659, 2003.

32. CHEN V.Z., LI J. International reverse spillover effects on parent firms: Evidences from emerging-market MNEs in developed markets. European Management Journal, 30, 204, 2012.

33. PIPEROPOULOS P., WU J., WANG C. Ootward FDI, location choices and innovation performance of emerging market enterprises.Research Policy, 47, 232, 2018.

34. KUMAR V., SINGH D., PURKAYASTHA A., POPLI M., GAUR A. Springboard internationalization by emerging market firms: Speed of first cross-border acquisition. Journal of International Business Studies, 51, 172, 2020.

35. VLAJČIĆ D, CAPUTO A., MARZI G., DABIĆ M. Expatriates managers' cultural intelligence as promoter of knowledge transfer in multinational companies. Journal of Business Research, 94, 367, 2019.

36. CHEN K.M., YANG S.F. Impact of Outward Foreign Direct Investment on Domestic R\&D Activity: Evidence from Taiwan's Multinational Enterprises in Low-wage Countries.Asian Economic Journal, 27, 17, 2013.

37. ZHOU Y., JIANG J.J., YE B., HOU B.J. Green spillovers of outward foreign direct investment on home countries: Evidence from China's province-level data. Journal of Cleaner Production, 215, 829, 2019.

38. TANG J., ALTSHULER R. The spillover effects of outward foreign direct investment on home countries: Evidence from the United States.Proceedings of the Annual Conference on Taxation, 107, 1, 2014.

39. LI J., STRANGE R., NING L. Outward foreign direct investment and domestic innovation performance: Evidence from China.International Business Review, 25, 1010, 2016.

40. AMANN E., VIRMANI S. Foreign direct investment and reverse technology spillovers: The effect on total factor productivity.Economic Studies, 1, 129, 2015.

41. LYCHAGIN S., PINKSE J., SLADE M.E., REENEN J.V. Spillovers in space: Does geography matter?The Journal of Industrial Economics, 64, 295, 2016.

42. QIU H.H., YANG J. An assessment of technological innovation capabilities of carbon capture and storage technology based on patent analysis: A comparative study between china and the United States. Sustainability, 10, 877, 2018.

43. GEUM Y., KIM M. How to identify promising chances for technological innovation: Keygraph-based patent analysis. Advanced Engineering Informatics, 46, 101155, 2020.

44. PORTER M.E., STERN S. Measuring the ideas production function: Evidence from international patent output. Nber working paper series, 2000.

45. BROBERG T., BERG C.,SAMAKOVLIS E. The economywide rebound effect from improved energy efficiency in Swedish industries - A general equilibrium analysis. Energy Policy, 83, 26, 2015.

46. JIN S.H. The effectiveness of energy efficiency improvement in a developing country: Rebound effect of residential electricity use in South Korea. Energy Policy, 35, 5622, 2007. 
47. LIN B., LIU H. A study on the energy rebound effect of China's residential building energy efficiency. Energy and Buildings, 86, 608, 2015.
48. FILIPPINI M., ZHANG L. Estimation of the energy efficiency in Chinese provinces.Energy Efficiency, 9, 1315, 2016. 